\title{
AUDIOVISUAL EDUCATION AND BREASTFEEDING PRACTICES: A PRELIMINARY REPORT
}

\author{
V.C. Nikodem, G.J. Hofmeyr, T.R. Kramer, \\ A.M.Gülmezoglu, and A. Anderson.*
}

\begin{abstract}
A randomized control trial was conducted at the Coronation Hospital, to evaluate the effect of audiovisual breastfeeding education. Within 72 hours after delivery, 340 women who agreed to participate were allocated randomly to view one of two video programmes, one of which dealt with breastfeeding. To determine the effect of the programme on infant feeding a structured questionnaire was administered to 108 women who attended the six week postnatal check-up. Alternative methods, such as telephonic interviews (24) and home visits (30) were used to obtain information from subjects who did not attend the postnatal clinic. Comparisons of mother-infant relationships and postpartum depression showed no significant differences. Similar proportions of each group reported that their baby was easy to manage, and that they felt close to and could communicate well with it. While the overall number of mothers who breast-fed was not significantly different between the two groups, there was a trend towards fewer mothers in the study group supplementing with bottle feeding. It was concluded that the effectiveness of audiovisual education alone is limited, and attention should be directed towards personal follow-up and support for breastfeeding mothers.
\end{abstract}

\section{INTRODUCTION}

Infection is the main cause of infant death in countries with a high infant mortality rate. Ashraf et al.(1990) have shown that even partial breastfeeding can protect infants from neonatal infections and that early colostrum feeding should be promoted.

Despite the fact that at least $97 \%$ of women are physiologically capable of breastfeeding their babies successfully and the recommendation that breastfeeding should not be supplemented before the age of four months (Royal College of Midwives 1988), research from many parts of the world has shown low and declining rates of breastfeeding success.(Martin \& White 1988). At Coronation Hospital only $40 \%$ of first time mothers are exclusively breastfeeding their babies at 6 weeks, another $33 \%$ are supplementing their babies' needs with bottle feeds and $27 \%$ are giving only bottle feeds to their babies. Thirty-six percent have introduced solids before 6 weeks (Hofmeyr et al. 1991).

The main reasons women give for early discontinuation of breastfeeding are insufficient milk, nipple trauma and breast engorgement (Hofmeyr et al. 1991, Inch \& Renfrew 1989). In theory most of these problems could be overcome by teaching specific breastfeeding techniques such as correct positioning of the baby on the breast. If these skills could be communicated effectively by means of an audiovisual programme alone, this would provide scope for large-scale inexpensive educational programmes. We therefore investigated the effect of audiovisual education as a simple intervention in breastfeeding success.

\section{SUBJECTS AND METHODS}

An audiovisual education programme concentrating on specific breastfeeding techniques to promote long-term breastfeeding was produced in association with the Central Television Service of the University of the Witwatersrand.

The study was conducted at the Coronation Hospital which serves mainly low-income urban people. It was linked to the South African Medical Research Council's "Birth to Ten" cohort study. Three hundred and forty women who had commenced breastfeeding and who agreed to participate were allocated, by means of randomly ordered cards in sealed opaque envelopes, to view one of two health education video programmes within $72 \mathrm{hrs}$ after delivery. The first programme gave information and specific motivation concerning the importance of breastfeeding and the correct positioning of the baby. The second gave information about healthy eating habits for adults.

To determine the effect of the study programme on infant feeding, a structured questionnaire was administered at the 6 week postnatal visit. All interviews were done by two registered midwives who administered a structured questionnaire at the postnatal clinic (108), telephonically (24) or at home visits (30). The midwives were unaware of the group allocation, of the mothers. The questionnares were either conducted in Afrikaans or English as all the mothers could understand one of these two languages. Despite a concerted attempt made to follow up those who failed to attend the post natal clinic, we were able to follow up only $162(47.6 \%)$ of subjects within 12 weeks after delivery.

Although the follow-up rate was only $47.6 \%$, re-analyses of the baseline 
variables showed no differences between the two groups which were followed up and we have no theoretical basis on which to expect that there should have been any bias introduced by the low follow-up rate; nevertheless, this remains a matter of concern.

All completed questionnaires were coded and statistical calculations were performed using the CMS statistical package through the Institute for Biostatistics, South African Medical Research Council, as well as Epi Info (World Health Organisation). Statistical comparisons of continuous variables were analyzed using the Student t-test, Mann Whitney $U$ test and proportions were compared by means of $95 \%$ confidence interval (CI) of the odds ratio and the chi-squared test. To determine whether the difference between outcomes might be the result of chance, statistical tests of chance were used where a $p$ value is often given. All this indicates is the likelihood that the difference between outcomes occurred by chance. Thus a $p$ value less than 0.05 indicates a less than 5\% likelihood that the difference is due to chance. It is important not to confuse the degree of certainty indicated by the $p$ value with the clinical importance of the difference. It is possible for a study using large numbers to have a high significant value when the actual size of the difference is too small to be clinically meaningful although more often the opposite happens. Because of small numbers studied, a difference between groups which might be very important cannot be proved to be statistically significant.

For this reason many researchers prefer to use confidence intervals to indicate the range within which the true difference between alternative forms of care is likely to lie. Confidence intervals provide more information than $p$ values because a confidence interval is defmed by two numbers rather than the single one which denotes a $p$ value. If the values do not include 1 , the $95 \%$ confidence interval of the estimate of the difference between two observations confirms that the observed difference is unlikely to be due to chance; in addition, it provides potentially important information about which of two methods is liklier to lead to a reduction or increase in the outcome. The odds ratio thus reflects the chances of reduction or increase of the effect under study. Instead of giving a p-value, we say that we are $95 \%$ confident that the true difference lies within this range (Chalmers, 1989).

\section{RESULTS}

Socio-demographic characteristics.

There were no significant differences between the socio-demographic characteristics of the two groups confirming that the randomization was effective and that similarity of the groups was not compromised by the loss to follow-up (Table 1). you think your baby is special, in-between or ordinary. Pitt's Depression Questionnaire (Pitt,1968) was used to measure the depression scores and is a scale designed specifically to assess postpartum depression. This instrument was selected because it is reliable and valid. It includes all the major clinical features associated with postpartum depression and does not specify low moderate or high depression ratings but

\begin{tabular}{|c|c|c|c|c|c|c|}
\hline \multicolumn{7}{|c|}{$\begin{array}{c}\text { Table } 1 \\
\text { Soclo-demographic characteriatlcs, expressed as mean values (range) } \\
\text { or proportions (percent) }\end{array}$} \\
\hline & $\begin{array}{l}\text { Study } \\
\text { n }\end{array}$ & & & $\begin{array}{l}\text { Contro } \\
n\end{array}$ & & \\
\hline Age & 83 & 25.4 & $(15-42)$ & 79 & 24.5 & $(15-40)$ \\
\hline Primigravida & 83 & 31 & $(37.3 \%)$ & 77 & 37 & $(48.1 \%)$ \\
\hline Unmarried & 83 & 53 & $(63.8 \%)$ & 79 & 44 & $(55.7 \%)$ \\
\hline Lives with family & 83 & 38 & $(45.8 \%)$ & 79 & 38 & $(48.7 \%)$ \\
\hline \multicolumn{7}{|l|}{ Language: } \\
\hline Afrikaans & 83 & 54 & $(65.1 \%)$ & 79 & 52 & $(65.8 \%)$ \\
\hline English & 83 & 16 & $(19.3 \%)$ & 79 & 19 & $(21.4 \%)$ \\
\hline Other & 83 & 13 & $(15.6 \%)$ & 79 & 8 & (10.2\%) \\
\hline \multicolumn{7}{|l|}{ Education: } \\
\hline Standard 8 & 83 & 42 & $(50.6 \%)$ & 78 & 38 & (48.7\%) \\
\hline Employed before pregnancy & 82 & 50 & $(61.0 \%)$ & 79 & 49 & $(62.0 \%)$ \\
\hline Monthly income < R1000-00 & 73 & 55 & $(75.3 \%)$ & 69 & 48 & $(69.5 \%)$ \\
\hline
\end{tabular}

No significant difforences

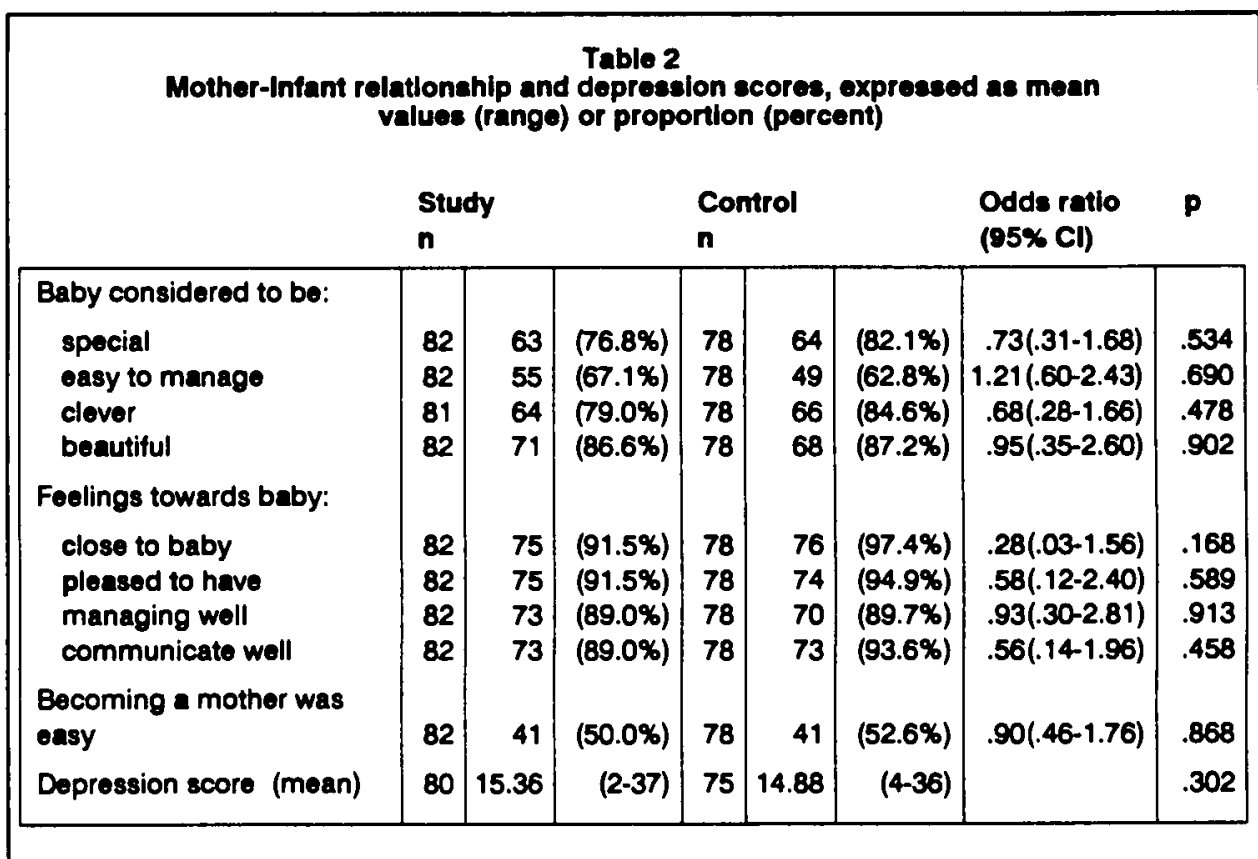

Mother-infant relationship and depression scores.

Questions that were used to measure mother-infant relationship did not constitute a single measuring instrument but were essentially rating scales eg. Do rather facilitates the location of scores on a continuum of postpartum depression. The groups did not differ significantly with respect to measures of the mother-infant relationship, or to the depression scores as measured with the Pitt's depression inventory (Table 2). 
Breast-feeding practices.

While the overall number of mothers who breastfed was not significantly different between the two groups (Table 3), there was a tendency for more mothers in the control group to supplement with bottle feeding. When asked about the reasons for introducing the bottle, similar proportions reported that their breastmilk was inadequate. A more flexible approach to feeding was adopted by the study group. The duration of 'breastfed only' was similar in both groups.
Gagliano (1988) has reviewed 25 methodologically sound studies on in-patient video education and one of her conclusions was that audiovisual stimulation increases short-term knowledge. As a once-off intervention we chose the postnatal period as this would be the time when preoccupations with labour and birth would be over and the mothers would be involved maximally with their babies and be most receptive to information on breast-feeding. They also would be able to put information into practice immediately whereas information provided in the antenatal

Table 3

Breasteeding practices, expressed as mean values (range) and proportions (percent)

\begin{tabular}{|c|c|c|c|c|c|c|c|c|}
\hline & \multicolumn{2}{|c|}{$\begin{array}{l}\text { Study } \\
n\end{array}$} & & \multicolumn{2}{|c|}{$\begin{array}{l}\text { Control } \\
n\end{array}$} & & $\begin{array}{l}\text { Odds ratio } \\
\text { (95\% Cl) }\end{array}$ & $\mathbf{p}$ \\
\hline Breastfed only & 83 & 30 & $(36.1 \%)$ & 79 & 23 & $(29.1 \%)$ & $1.38(.68-2.81)$ & .431 \\
\hline Breast \& bottle & 83 & 35 & $(42.2 \%)$ & 79 & 39 & $(49.4 \%)$ & $.75(.38-1.46)$ & .446 \\
\hline Bottle only & 83 & 18 & $(21.7 \%)$ & 79 & 17 & $(21.5 \%)$ & $1.01(.45-2.28)$ & .868 \\
\hline Time breastfed only (days) & 83 & 30.9 & $(7-42)$ & 78 & 30.3 & $(7-42)$ & & .766 \\
\hline \multicolumn{9}{|l|}{$\begin{array}{l}\text { Main reason for starting } \\
\text { bottle-feeding: }\end{array}$} \\
\hline return to work & 53 & 8 & $(15 \%)$ & 56 & 11 & $(19.6 \%)$ & $.73(.24-2.19)$ & .709 \\
\hline believes bottle better & 53 & 1 & $(1.8 \%)$ & 56 & 2 & $(3.5 \%)$ & $.52(.01-10.31)$ & 1.00 \\
\hline baby III & 53 & 2 & $(3.7 \%)$ & 56 & 0 & $10 \%$ & undefined & .234 \\
\hline breast milk insufficient & 53 & 35 & $(66 \%)$ & 56 & 35 & $(62.5 \%)$ & $1.17(.49-2.76)$ & .853 \\
\hline breastfeeding problems & 53 & 5 & $(9.4 \%)$ & 56 & 7 & $(12.5 \%)$ & $.73(.17-2.89)$ & .837 \\
\hline other & 53 & 2 & $(3.7 \%)$ & 56 & 1 & $(1.7 \%)$ & $2.16(.11-129.52)$ & .611 \\
\hline Given food other than milk & 83 & 25 & $(30.1 \%)$ & 79 & 22 & $(27.8 \%)$ & $1.12(.54-2.33)$ & .884 \\
\hline Other food before 4 weeks & 25 & 9 & $(36 \%)$ & 22 & 9 & $(40.9 \%)$ & $.81(.21-3.10)$ & .964 \\
\hline Feeding on request & 82 & 27 & $(32.9 \%)$ & $\pi$ & 17 & $(22.1 \%)$ & $1.73(.81-3.74)$ & .176 \\
\hline
\end{tabular}

Baby problems and advice or treatment sought.

Mothers in the control group experienced slightly more baby problems, such as vomiting, colds and diarrhoea (Table 4). Significantly more mothers in the control group sought medical advice or treatment for their babies (CI .21 - .87).

\section{DISCUSSION}

Education is "the positive influencing of ... (people) with the specific purpose of effecting changes of significant value" (van Rensburg \& Landman 1986). The objective of this study was to determine whether meaningful improvements in breastfeeding success could be achieved by means of single exposure to a video programme. The programme aimed to create a positive attitude to breastfeeding and to give information about breastfeeding techniques and the overcoming of common problems.

The decision to breast-feed is usually made early durimg pregnancy (Beske \& Gravis 1982) and antenatal education appears to be effective in increasing knowledge about breastfeeding but not the incidence or duration of breastfeeding (Kaplowitz \& Olsen 1983).

The main cause of high infant mortality rates in communities without access to safe alternative feeding methods is gastroenteritis resulting directly from bottle-feeding (Irwig \& Ingle 1984). More mothers in the control group mentioned that their babies had had diarrhoea already and that they had sought medical advice before 6 weeks (Table 4). It is important to consider using audiovisual education if it reduces the use of bottle-feeding even by a small margin.

\section{CONCLUSIONS}

Because of the great importance of breast-feeding, the marginal benefits suggested by the trends in this study may be sufficient to justify the routine use of audiovisual education, particularly as it is not labour intensive and can be used on a large scale. However we would strongly recommend that such a programme be backed up by individual help, and support with breast-feeding education to family members and ongoing breast-feeding support services. Future research should be directed towards evaluation of the effectiveness of such an integrated programme.

\section{RECOMMENDATIONS FOR FUTURE RESEARCH}

This study purposefully investigated the isolated effect of audiovisual education

period may be forgotten by the time breastfeeding starts.

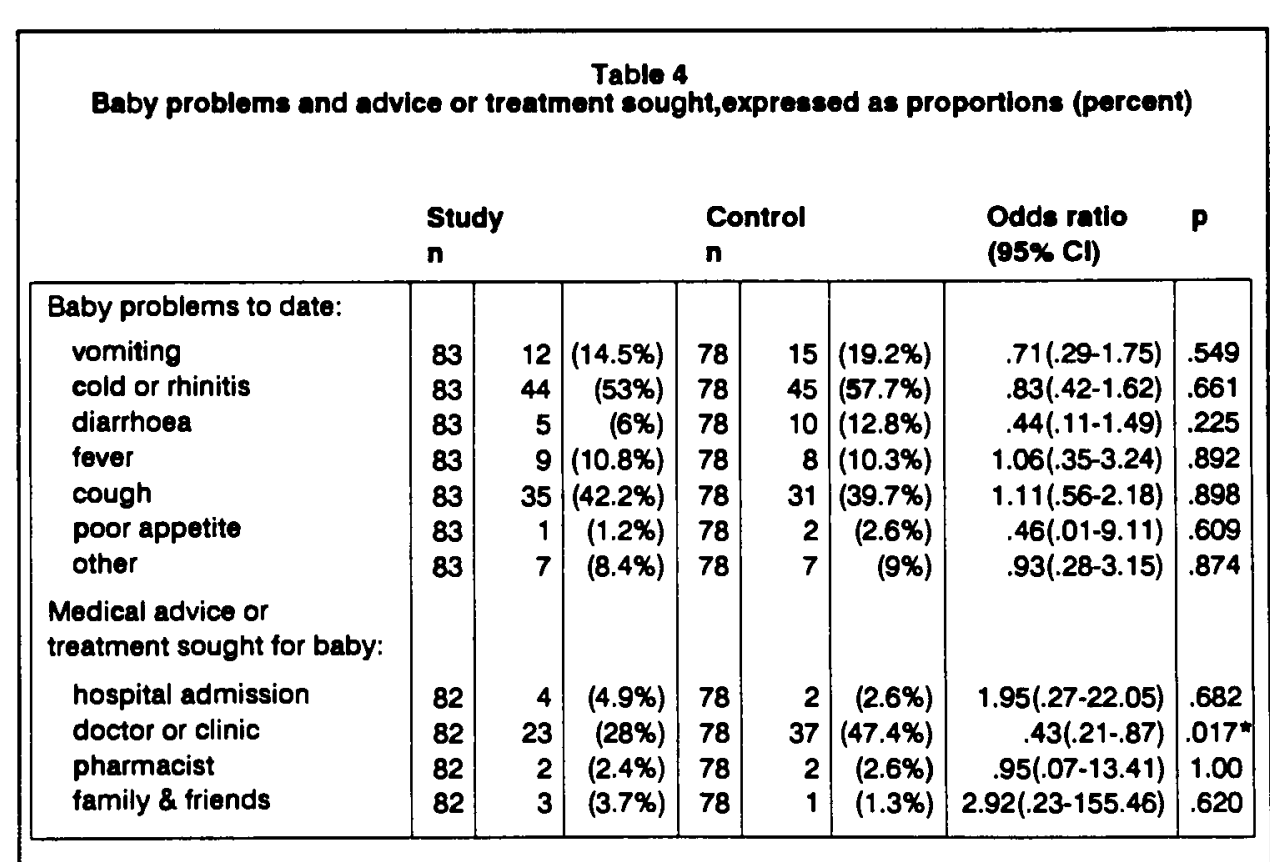


alone. Future research should be directed towards identifying the most effective methods of promoting successful breasfeeding, using a combination of education of mothers, education of professional staff to provide support consistent with the educational material, and person to person follow up and supportive encouragement (Ross, Loening \& Mbele, 1987).

\section{LIMITATIONS OF THIS STUDY}

The low rate of follow-up remains a matter of concern. Lack of response to certain variables in the questionnaire explains the variation in the sample sizes but does not add to change of the results.

\section{ACKNOWLEDGMENTS}

We acknowledge the assistance of the nursing staff in the Obstetric department of the Coronation Hospital especially Ursula Benjamin and Rosaline Cambell who contributed to data collection; Central Television Service of the University of the Witwatersrand for funding and producing the video, and the South African Medical Research Council.

\section{REFERENCES}

ASHRAF R.N., JALIL F., ZAMEN S., KARLBERG J., KHAN S.R., LINDBLAD B.S. AND HANSON L.A. (1990). Breastfeeding protects against neonatal sepsis im high risk population. Arch: Dis. Child. 66. 488-490.

BESKE E.J. AND GRAVIS M.S. (1982). Important factors in breastfeeding success. Matem Child Nurs, 7, 174-179.

CHALMERS I. (1989). In Effective Care in Pregnancy and Childbirth. (Chalmers I., Enkin M. \& Keirse
M.J.N.,eds), Oxford University Press: Oxford, 21-22.

GAGLIANO M.E. (1988). A Literature Review on the Efficacy of Video In Patient Education. Journal of Medical Education.J. Med. Educ., 63, 785-791.

HOFMEYR G.J., NIKODEM V.C., WOLMAN W-L., CHALMERS B.E. AND KRAMER T. (1991). Companionship to modify the clinical birth environment: effects on progress and perception of labour, and breastfeeding. Br J Obstet Gynaecol., 98, 756-764.

INCH S. (1989). Antenatal preparation for breastfeeding. In Effective Care in Pregnancy and Childbirth. (Chalmers I., Enkin M. \& Keirse M.J.N.,eds), Oxford University Press: Oxford, p. 335.

INCH S. AND RENFREW M.J. (1989). Common breastfeeding problems. In Effective Care in Pregnancy and Childbirth. (Chalmers I., Enkin M. \& Keirse M.J.N.,eds),Oxford University Press: Oxford, p. 1386.

IRWIG L.M. AND INGLE R.F. (1984). Childhood mortality rates, infant feeding and the use of health services in rural Transkei. SAMJ, 66, 608-613.

KAPLOWITZ D.D. AND OLSEN C.M. (1983). The effect of an Education Program on the Decision to Breastfeed. Journal of Nutrition Education, 15, 2, 61-65.

MARTIN J. AND WHITE A. (1988). Infant Feeding 1985. London: HMSO

PITT B. (1968). "Atypical" depression following childbirth. British Joumal of Psychiatry. 114, 1325-1335

ROYAL COLLEGE OF MIDWIVES. (1988). Successful Breastfeeding A
Practical Guide for Midwives (and others supporting breastfeeding mothers); Holywell Press: Oxford. p. 1

ROSS S.M., LOENING W.E.K. AND MBELE B.E. (1987). Breast-feeding Support. SAMJ, 72, 357-358.

ROSS S.M., LOENING W.E.K. AND VAN MIDDELKOOP A. (1983). Breast-feeding - evaluation of a health education programme. $S A M J$, 64 , 361-363.

SALARIYA E., EASTON P. AND CATER J. (1979). Early and often for best results. Nursing Mirror. 15-17

VAN RENSBURG C.J.J. AND LANDMAN W.A. (1986). Notes on Fundamental-Pedagogic Concepts An Introductory Orientation. Transvaal: N.G.Kerkboekhandel. p. 306.
V. CHERYL NIKODEM BA(CUR)
Ed/COMm RN/RM

G. JUSTUS HOFMEYA MRCOG (Professor)

TAMI R. KRAMER MB ch B

A METIN GŨMEZOGLU MD APRIL ANDERSON *

Department of Obstetrics and Gynaecology, Coronation Hospital and University of the Witwatersrand.

- Department of Biostatistics, South African African Medica Research Council. 